\title{
CLINICAL EXPERIENCE WITH PLV-2 (OCTAPRESSIN) AS A LOCAL HAEMOSTATIC AGENT
}

\author{
Deirdre M. M. Gillies, M.B., Ch.B., AND William J. FarLey, M.D., F.R.C.P.(C)
}

THE SEARCH for an effective local haemostatic agent compatible with the various anaesthetic agents used today is a continuing one. It would seem that 2-phenylalanine 8-lysine vasopressin (PLV-2 or Octapressin) meets these criteria. This drug is a potent vasoconstrictor whose main site of action is probably on the capacitance vessels of the microcirculation. ${ }^{1}$ This may explain the lack of reactive hyperaemia with its use. It has been shown that PLV-2 is a good, safe local haemostatic agent in vaginal surgery. ${ }^{2}$ In ear, nose, and throat surgery results have been more difficult to interpret. ${ }^{3-\tau}$ Reports so far suggest that it is safe to use with halothane and cyclopropane. ${ }^{8-11}$ The present study was undertaken to determine whether PLV-2 could safely be used with halothane, cyclopropane, and methoxyflurane, and whether blood loss could be significantly reduced and operative visibility improved.

\section{METHOD}

PLV-2 was used in 206 surgical procedures. As seen in Table I, the operative procedures are divided into three main groups: (1) tonsillectomy in children and adults, (2) vaginal surgery and (3) lumbar discoidectomy. The classification "others" includes excision of pilonidal cyst (four cases), septal reconstruction (three cases), bleeding oesophageal varices (one case), and tibial bone graft (one case).

TABLE I

Classification of Cases

\begin{tabular}{lcr}
\hline Procedure & $\begin{array}{c}\text { Without } \\
\text { PLV-2 }\end{array}$ & $\begin{array}{c}\text { With } \\
\text { PLV-2 }\end{array}$ \\
\hline \hline T \& A & & \\
$\quad \begin{array}{l}\text { adults } \\
\text { children }\end{array}$ & 63 & 36 \\
Vaginal surgery & 144 & 66 \\
$\quad$ conization of cervix & & 9 \\
$\quad \begin{array}{l}\text { anterior-posterior repairs and } \\
\text { vaginal hysterectomy }\end{array}$ & 0 & \\
Lumbar discoidectomy & 48 & 35 \\
Other & 25 & 35 \\
Total & 0 & 25 \\
\hline
\end{tabular}

During the trial period no patient was excluded from the series because of concurrent disease. The group included five cases of essential hypertension, two

-Department of Anaesthesia, Queen Elizabeth Hospital of Montreal and McGill University. 
of myocardial ischaemia and two asthmatics. These patients were compared with a similar group who had not received any local haemostatic agent.

Premedication, anaesthetic agent, and technique used were left to the choice of the individual anaesthetist (Table II). The distribution of agents used was similar in the two series. All patients were intubated, and respiration was assisted or controlled throughout the operation.

TABLE II

Anaesthetic Agents Used in Association with PLV-2

\begin{tabular}{lrrrrr}
\hline & E.N.T. & Gynaecology & Discs & Others & Total \\
\hline Halothane & & & & & \\
$\quad$ semi-closed & 73 & 33 & 24 & 19 & $\mathbf{1 4 9}$ \\
$\quad$ closed circuit & 0 & 1 & 9 & 2 & 12 \\
Methoxyflurane & 13 & 2 & 2 & 0 & $\mathbf{1 7}$ \\
Cyclopropane & 16 & 8 & 0 & 1 & 25 \\
Total & 102 & 44 & 35 & 22 & 203 \\
\hline
\end{tabular}

PLV-2 was used in concentrations varying from 5 pressor units per c.c. to 5 units per 100 c.c. Normal saline was the diluent. The dose adminstered varied from 0.75 to 15 pressor units.

\section{Techniques of Injection}

Tonsillectomy. PLV-2 was injected into the extracapsular area at the upper pole, the middle of the anterior pillar and at the lower pole of each tonsil. In addition, the region of the lingual tonsil was infiltrated. In a few patients PLV-2 was only injected on one side and an attempt was made to compare the blood loss from the two sides. This did not prove to be feasible. Packs soaked in a solution of PLV-2 were placed in the tonsillar and adenoid fossae in a few patients. In the majority of patients in this group the concentration of PLV-2 used was 5 pressor units per 10 c.c. In the latter part of the study the concentration was increased to 5 units in 1 c.c.

Vaginal surgery. Subcutaneous infiltration of both the anterior and the posterior vaginal wall was done in patients undergoing pelvic floor repair. In the operation of cervical conization, the drug was infiltrated circumferentially around the cervix. In these patients the concentration of PLV-2 which produced satisfactory results was 5 units in 25 c.c.

Lumbar discoidectomy. The line of incision was infiltrated with solution to the depth of the spinous processes. In addition, if a fusion was to be done, the area of the bone donor site was infiltrated. The concentration of drug used in this group was 5 units in 25 c.c.

An accurate recording of systolic and diastolic blood pressure and of pulse rate was kept for every patient. Blood loss was measured volumetrically in tonsillectomies and by a modified gravimetric method in all other cases. Blood volume was estimated on the basis of body weight: $80 \mathrm{c.c} . / \mathrm{kg}$. for children 12 years and under, $70 \mathrm{c.c} . / \mathrm{kg}$. for adults. The blood loss was then calculated as a percentage of estimated blood volume. In the majority of patients in this study Lead II of 
the electrocardiograph was monitored continuously throughout the operation. In addition, at the end of the procedure, the surgeon wrote his comments regarding the effectiveness of PLV-2 as a haemostatic agent.

\section{Results}

It was difficult to assess the comments made by the otolaryngologists and the orthopaedic surgeons. Many were obviously related to the mood of the surgeon on the particular day. However, the gynaecologists were almost always impressed by the local ischaemia produced by PLV-2, so that this drug is still in great demand. The general surgeons have found that the drug is of great assistance in operations for excision of pilonidal cysts. Since this study was done, many more of these procedures have been carried out using PLV-2, and the results have been most favourable.

There was no significant difference in the mean blood loss in patients undergoing tonsillectomy and lumbar discoidectomy, with and without PLV-2 (Table III). In vaginal surgery, the figures obtained are more impressive (Table IV).

TABLE III

Blood Loss in Tonsillectomy and Lumbar Discoidectomy

\begin{tabular}{|c|c|c|c|}
\hline & \multicolumn{2}{|c|}{ Tonsillectomy } & \multirow{2}{*}{$\begin{array}{c}\text { Lumbard } \\
\text { discoidectomy }\end{array}$} \\
\hline & adults & children & \\
\hline \multicolumn{4}{|l|}{ Procedures } \\
\hline $\begin{array}{l}\text { without PLV-2 } \\
\text { with PLV-2 }\end{array}$ & $\begin{array}{l}63 \\
36\end{array}$ & $\begin{array}{r}144 \\
66\end{array}$ & $\begin{array}{l}25 \\
35\end{array}$ \\
\hline $\begin{array}{l}\text { Mean blood loss } \\
\text { without PLV-2 (\%) } \\
\text { S.D. }\end{array}$ & $\begin{array}{l}5.82 \\
3.04\end{array}$ & $\begin{array}{l}8.79 \\
3.48\end{array}$ & $\begin{array}{l}8.77 \\
4.12\end{array}$ \\
\hline $\begin{array}{l}\text { with PLV-2 (\%) } \\
\text { S.D. }\end{array}$ & $\begin{array}{l}4.75 \\
2.75\end{array}$ & $\begin{array}{l}9.32 \\
3.74\end{array}$ & $\begin{array}{l}9.64 \\
4.92\end{array}$ \\
\hline
\end{tabular}

TABLE IV

Results in Vaginal Surgery

\begin{tabular}{lcc}
\hline \hline & $\begin{array}{c}\text { Without } \\
\text { PLV-2 }\end{array}$ & $\begin{array}{c}\text { With } \\
\text { PLV-2 }\end{array}$ \\
\hline Number of cases & 48 & 35 \\
Mean duration of surgery (min.) & 145 & 95 \\
Mean blood loss (\% of total blood & 11.96 & 7.45 \\
volume) & 7.46 & 5.03 \\
\hline
\end{tabular}

The mean blood loss is reduced from 11.96 to 7.45 per cent. Applying Student's $t$-test to these figures, this reduction is significant at the one per cent level. It is interesting that blood transfusion was required in 30 of the 48 patients in the control series-the average volume transfused being one litre-whereas only 11 
of 35 patients in the PLV-2 series were transfused and the average volume given was 700 c.c. This could be reduced still further with experience in the use of the drug. The average duration of surgery was also markedly decreased and this can be attributed to the greatly improved visibility in the operative area. These results in vaginal surgery bear out the favourable impressions of the gynaecologists using PLV-2.

No significant increase in systolic or diastolic blood pressure was observed in any of the patients. Slowing of the pulse rate by at least 10 beats per minute within 10 minutes of the injection of PLV-2 was observed in 37 patients (Table V).

TABLE V

COMPLICATIONS

\begin{tabular}{lr}
\hline \hline Secondary haemorrhage & 3 \\
Wound breakdown & 2 \\
Pallor & 39 \\
Cardiac arrhythmias & 4 \\
Bradycardia & 37 \\
Other & 1 \\
\hline
\end{tabular}

The maximum slowing occurred in a child undergoing tonsillectomy, whose preinjection pulse rate was 110 per minute. Within five minutes of injection of PLV-2 the pulse rate slowed to 60 per minute. Various cardiac arrhythmias were seen during induction of anaesthesia but in only four did arrhythmias occur which could be related to the injection of PLV-2. These patients were healthy young adults undergoing tonsillectomy. The anaesthetic agent was halothane in three patients and cyclopropane in one. All developed ventricular extrasystoles within five minutes of injection of PLV-2 (Fig. 1). Normal cardiac rhythm returned very quickly i.e. within two to three minutes. None had shown any irregularity during induction of anaesthesia. No patient showed evidence of myocardial ischaemia as a result of use of the drug.

Pallor of the skin was common and developed soon after injection of PLV-2, suggesting that some of the drug must be absorbed rapidly from the site of injection.

In three patients haemorrhage occurred postoperatively. Two of these patients had had tonsillectomy performed, and bleeding occurred in the recovery room. Transfusion was required in both, but bleeding was controlled by packing of the tonsillar fossae. One patient developed a pelvic haematoma after vaginal hysterectomy and anterior colporrhaphy. This was diagnosed one week postoperatively and was probably not related to PLV-2.

In two gynaecological patients secondary suturing was required, on the sixth and twelfth postoperative days respectively. In one, the posterior repair broke down and the patient's previous history revealed that episiotomy wounds in the past had been very slow to heal. In the other patient, the apex of the anterior repair had not healed, but the gynaecologist did not feel that this could be attributed to the use of PLV-2.

One death occurred on the third postoperative day. This patient had mild hypertension which did not require treatment. She was anaesthetized with 


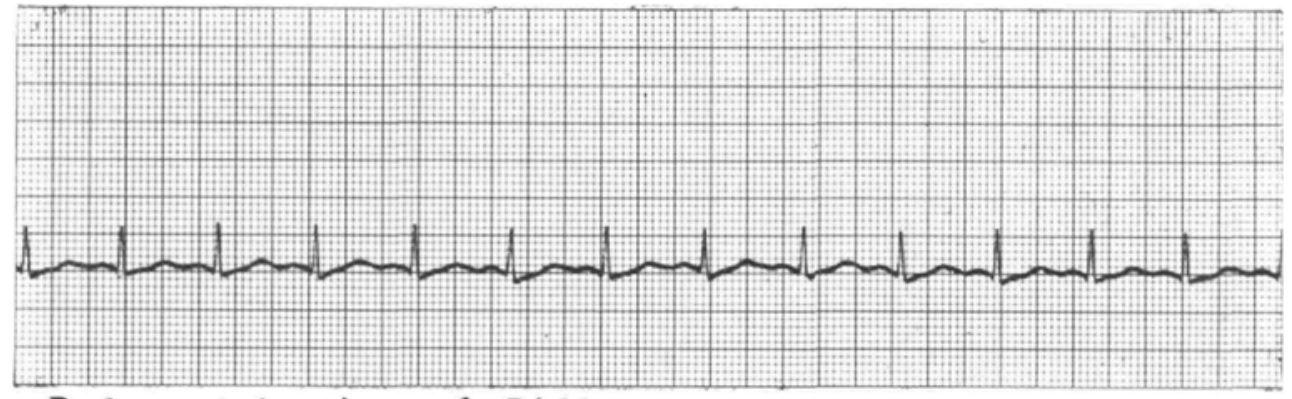

\section{Before injection of $\mathrm{PLV}_{2}$}

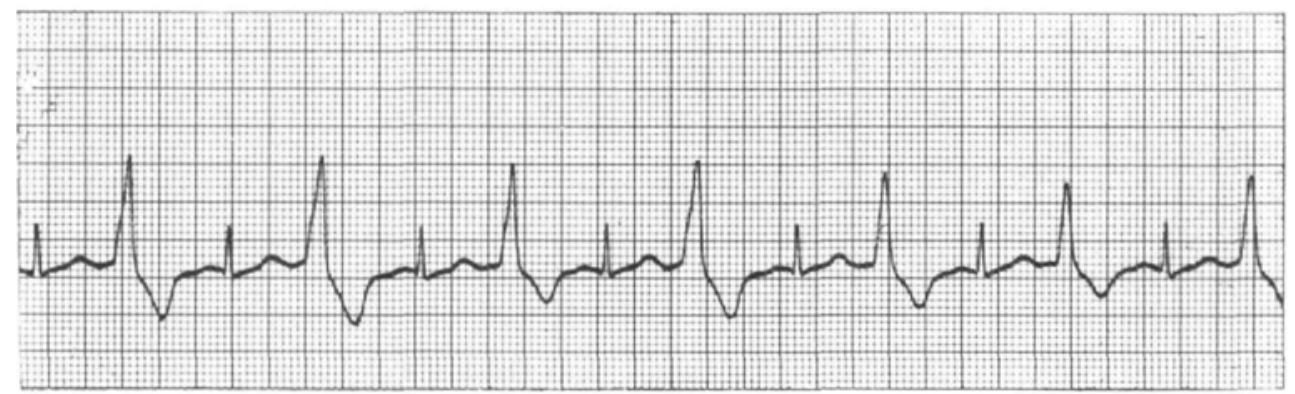

\section{4 minutes after $\mathrm{PLV}_{2}$}

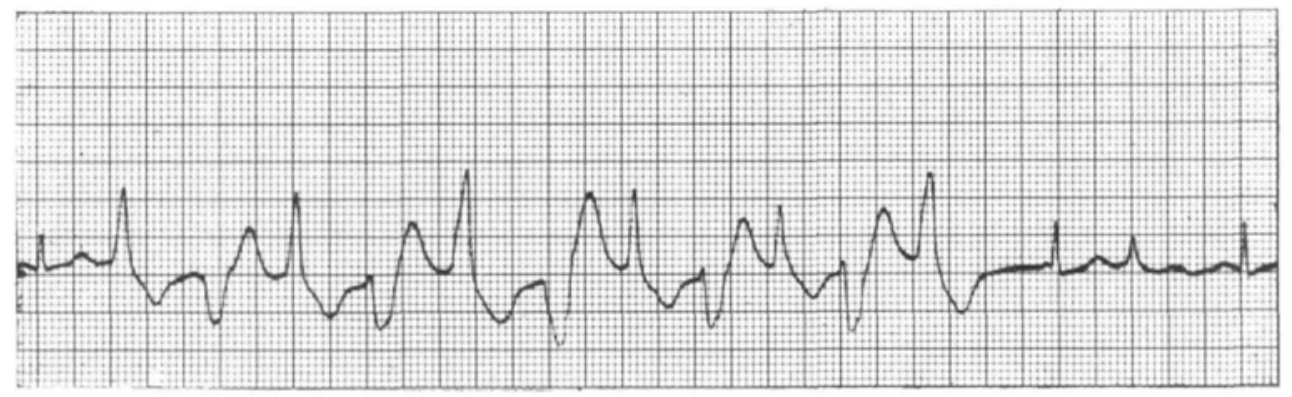

\section{6 minutes after $\mathrm{PLV}_{2}$}

Figune 1. Lead II of the electrocardiograph of patient undergoing T \& A under halothane anaesthesia.

halothane and given PLV-2. No significant change in blood pressure was recorded at any time, either during operation or in the recovery period. Death resulted from pontine haemorrhage. Because of the normality of the immediate postoperative period it was not considered that PLV-2 was implicated in this outcome.

\section{Conclusions}

It would appear that PLV-2 is a useful haemostatic agent in vaginal surgery, reducing both the blood loss and the operative time. We were unable to demonstrate similar beneficial results in ear, nose, and throat surgery and in lumbar disc surgery. 
Four patients developed cardiac arrhythmias. All were ventricular extrasystoles. Three of these patients received halothane anaesthesia and one cyclopropane. The arrhythmias appeared to be related in time to the injection of the drug, but the possibility that light anaesthesia and surgical stimulation may have been responsible for these irregularities, rather than the haemostatic agent, cannot be ruled out. This finding is not in accord with the observation of other investigators. ${ }^{8-11}$

\section{SUMMARY}

The purpose of this study is to assess the value of PLV-2 (Octapressin) as a local haemostatic agent used in conjunction with various common general anaesthetic agents and techniques. It has been used in 206 surgical procedures to improve surgical visibility and to reduce blood loss. These operations fall in three main groups: gynaecology by the vaginal route, lumbar discoidectomy, and tonsillectomy in children and adults. In order to assess the compatibility of PLV-2 with cyclopropane, halothane, and methoxyflurane, cardiac action has been monitored in the majority of cases.

It is concluded that PLV-2 is a valuable adjunct to vaginal surgery, blood loss being reduced to a minimum and visibility so improved that surgery can ve accomplished with greater accuracy and speed. When PLV-2 is used in nose and throat cases, its effects are not impressive; the reasons for this are not clear. PLV-2 does not appear to have significant systemic effects when used in this manner. It appears to be compatible with the anaesthetic agents used in this study.

\section{RÉSUMÉ}

Le but de cette étude est d'évaluer le PLV-2 (Octapressine) comme agent hémostatique local au cours de techniques d'anesthésie courantes, utilisant des agents d'emploi fréquent.

Le PLV-2 a été utilisé au cours de 206 interventions chirurgicales, à la fois pour améliorer la visiblité dans le champ opératoire et diminuer l'hémorrhagie. Ces interventions se classifient en trois groupes principaux: gynécologie par voie vaginale, discoidectomie lombaire et amygdalectomie chez l'enfant et l'adulte. Un moniteur cardiaque a été utilisée dans la majorité des cas en vue d'évaluer la compatibilité du PLV-2 avec le cyclopropane, le méthoxyflurane et l'halothane.

Il est conclu que le PLV-2 est un adjuvant précieux en chirurgie vaginale, alors qu'il minimise le saignement et améliore la visibilité dans le champ opératoire, permettant ainsi une chirurgie plus rapide et plus précise. En rhino-laryngologie, les effets sont moins impressionants; les raisons n'étant toutefois clarifiées. Employé d'après cette méthode, le PLV-2 ne produit pas d'effets systématiques significatifs et semble compatible avec les agents anesthésiques utilisés dans cette étude.

\section{ACKNOWLEDGMENTS}

The Octapressin used in this study was kindly supplied by Sandoz (Canada) Limited. 


\section{REFERENCES}

1. The Sites of Action of Vasoconstrictor Substances in the Vascular Bed of the Microcirculation. Triangle. 7: 77 (1965).

2. HOCHULI, E. \& KäSER, O. The Use of Octapressin as a Local Haemostatic in Obstetrics and Gynaecology. Triangle. 5: 363 (1962).

3. Mrssure, T. \& WEDER, A. Vergleichende Untersuchungen über das Verhalten des Kreislaufes bei der Tonsillektomie in LA mit vasokonstriktorischem Zusatz von Adrenalin bzw. PLV2. Pract. oto-rhino-laryng. 24: 249 (1962).

4. DE GrEnus, E. Die Kreislaufstabilisierung bei der Tonsillektomie in Lokalänasthesie. Pract. oto-rhino-laryng. 25: 145 (1963).

5. BolLoBAs, B. Oto-rhino-laryngologische Erfahrungen mit Octapressin. Wien. med. Wchnschr. 113: 277 (1963).

6. KowALCZUK, H. Zastosowanie Oktapresyny w Zabiegach otolaryngologicznych. Otolaryng. pol. 17: 85 (1963).

7. Light, G. A.; Rattenborg, C.; \& Holaday, D. A. A New Vasoconstrictor. Anesth. \& Analg. 44: 280 (1965).

8. Hunter, M. E. \& Gordon, R, A. Laboratory and Clinical Studies of 2-Phenylalanine8-Lysine Vasopressin (Octapressin). Canad. Anaesth. Soc. J. 13: 40 (1966).

9. Millar, R. A. Adrenaline and Halothane. Brit. J. Anaesth. 35: 335 (1963).

10. Katz, R. L. Epinephrine and PLV-2: Cardiac Rhythm and Local Vasoconstrictor Effects. Anesthesiology. 26: 619 (1965).

11. Shanks, C. A. Intravenous Octapressin during Halothane Anaesthesia: A Pilot Study. Brit. J. Anaesth. 35: 640 (1963). 